\title{
Continent urinary diversion and diverting colostomy in the therapy of non-healing pressure sores in paraplegic patients
}

\author{
D E Bejany MD, R Chao MD, P E Perito MD, * V A Politano MD
}

Department of Urology, University of Miami School of Medicine, PO Box 016217, Miami, Florida 33101, USA.

Immobilization and subsequent sacral decubitus or pressure sore formation is a danger faced by the paraplegic. We report on 4 patients treated with non-healing pressure sores. Three male patients had decubiti eroding into the posterior urethra and bladder neck area. One female patient had bladder neck and urethral loss secondary to Foley catheter erosion and a sacral pressure sore. All 4 had non-healing decubiti secondary to urinary contamination and, in addition, gross fecal contamination in the male patients. All patients failed previous muscular flaps and urinary diversion per suprapubic tube.

In the male patients, suprapubic continent urinary diversion included bladder neck mobilization, closure of the distal urethra by oversewing and patching with bovine dura, and augmentation of the bladder with a Miami pouch. Fecal diversion was provided with a sigmoid colostomy. In the female patient, continent diversion was performed by forming a Miami pouch. Total diversion allowed healing of the pressure sores and provided a simpler method of personal hygiene. Details of the diversion and case studies will be presented.

Keywords: continent urinary diversion; colostomy; decubitus ulcers; paraplegia.

\section{Introduction}

Decubitus ulcers or pressure sores have plagued physicians and patients for centuries, continuing today to impact on patient rehabilitation and healthcare costs. ${ }^{1.2}$ From 25 to $85 \%$ of patients with spinal cord injury develop pressure sores and a significant proportion require hospitalization for treatment. ${ }^{3}$ The paraplegic without adequate support systems is especially at risk for immobilization and subsequent sacral decubitus formation. We have treated 4 paraplegic patients at our institution with nonhealing pressure ulcers. Three patients had sacral decubiti with deep erosion into the posterior urethra and incontinence of urine and feces; one patient had only urinary incontinence secondary to erosion of the bladder neck-both situations precluded adequate healing. Urinary and fecal diversion was performed in the first 3 patients; urinary diversion via construction of a con-

\footnotetext{
*Correspondence.
}

tinent colonic urinary reservoir was performed in the fourth.

Since 1986, the goals of continent urinary diversion-adequate storage system, urinary continence and upper tract protectionhave been met at the University of Miami by construction of the 'Miami pouch'. The pouch includes a colonic segment for storage, a tapered distal ileum, reinforced ileocecal valve for continence and a nontunneled ureterocolonic anastomosis into a low pressure system for upper tract protection. Herein, we will describe our method of urinary and fecal diversion in the treatment of the paraplegic patients.

\section{Materials and methods}

Three men and one woman paraplegic, with a level of injury from T5 to T12, presented to our service with non-healing sacral decubitus ulcers and urinary incontinence. Patients' ages ranged from 29 to 42 years (Table I). All were paraplegic secondary to gun shot wounds. The 3 men had erosion of 
Table I Patient population

\begin{tabular}{lccc}
\hline $\begin{array}{l}\text { Patient/ } \\
\text { Diversion }\end{array}$ & $\begin{array}{c}\text { Age } \\
\text { (yrs) }\end{array}$ & Level & $\begin{array}{c}\text { Date of } \\
\text { injury }\end{array}$ \\
\hline $\begin{array}{l}\text { Mar 1989 } \\
2\end{array}$ & $38 \mathrm{M}$ & T5 & 1973 \\
Feb 1990 & $33 \mathrm{M}$ & T9 & 1985 \\
$3 \begin{array}{l}\text { Mar 1990 } \\
4\end{array}$ & $29 \mathrm{M}$ & T12 & 1984 \\
Jan 1991 & $42 \mathrm{~F}$ & T10 & 1974 \\
\hline
\end{tabular}

$\mathrm{M}=$ male $; \mathrm{F}=$ female.

the ulcer into the posterior urethra (Figs 1, 2) and bladder neck area with subsequent total urinary incontinence, the rectum being located in the superior aspect of the pressure sore. The female patient had complete erosion of her bladder neck and urethra secondary to prolonged Foley catheter pressure with total urinary incontinence, the rectum being located inferior to the ulcer (Fig 3). All 4 patients had sacral and ischial tuberosity decubitus ulcers down to the bone.

All 4 patients underwent urinary diversion, and the male patients underwent fecal diversion. Urinary diversion was performed with a Miami pouch, used either as an augmentation (Fig 4) or a complete pouch. Distal ileum, cecum and ascending colon were isolated to create the pouch. The colonic segment was opened on its antimesenteric border along the tenia, folded in a 'U' shape and the back wall was oversewn with double rows of running interlocking 3-0 vicryl sutures. A Mallecot catheter was placed in the reservoir and brought out through the previous appendiceal stump.

Tapering of the distal ileum and reinforcement of the ileocecal valve was now performed to achieve continence. The distal ileum was intubated with a 14 FR red rubber catheter. Allis clamps were placed on the antimesenteric border of the ileum and pulled to provide mild traction. Babcock clamps fixed the red rubber catheter in place. A GIA stapler was then applied

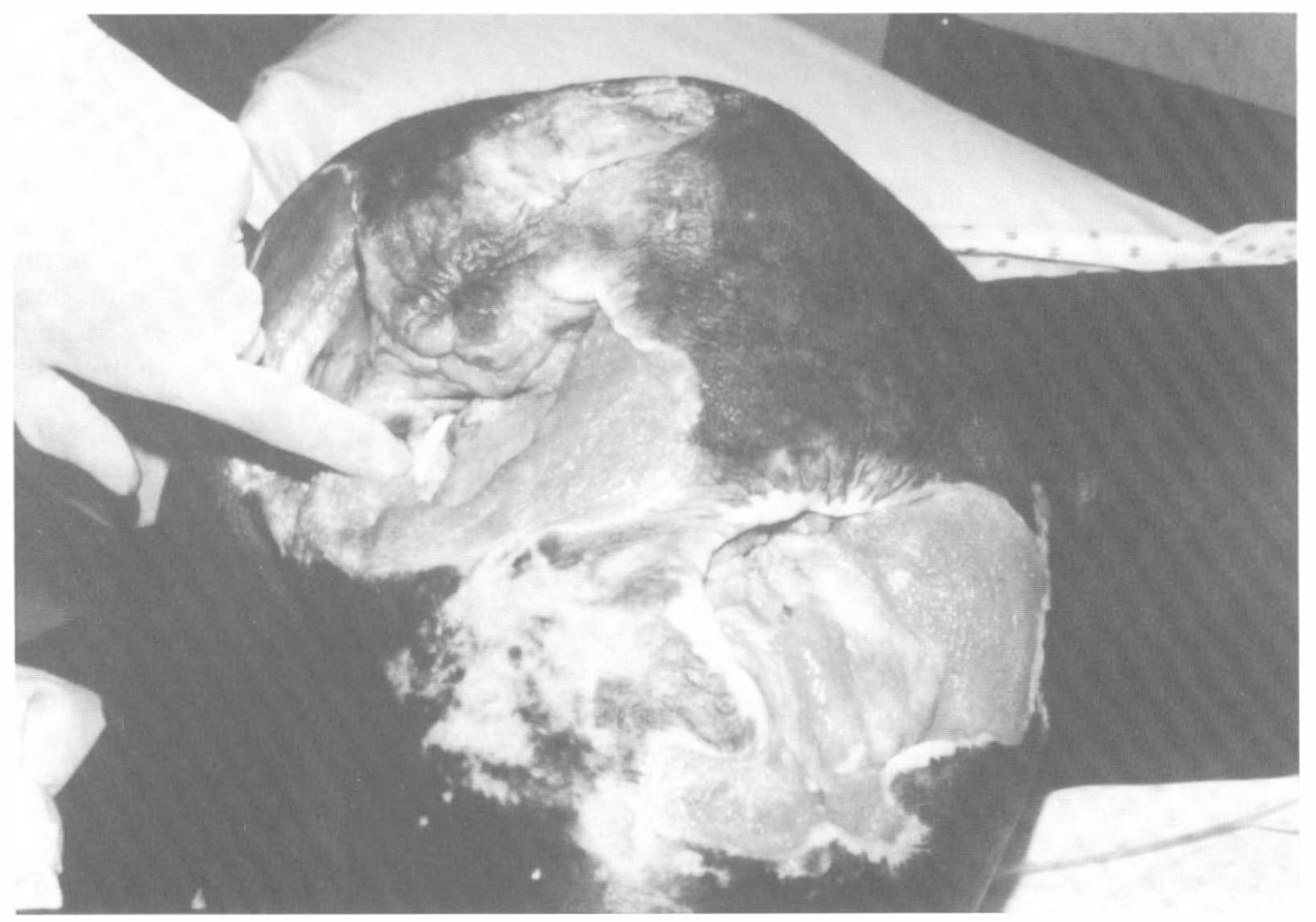

Figure 1 Patient 2 showing posterior urethra erosion. 


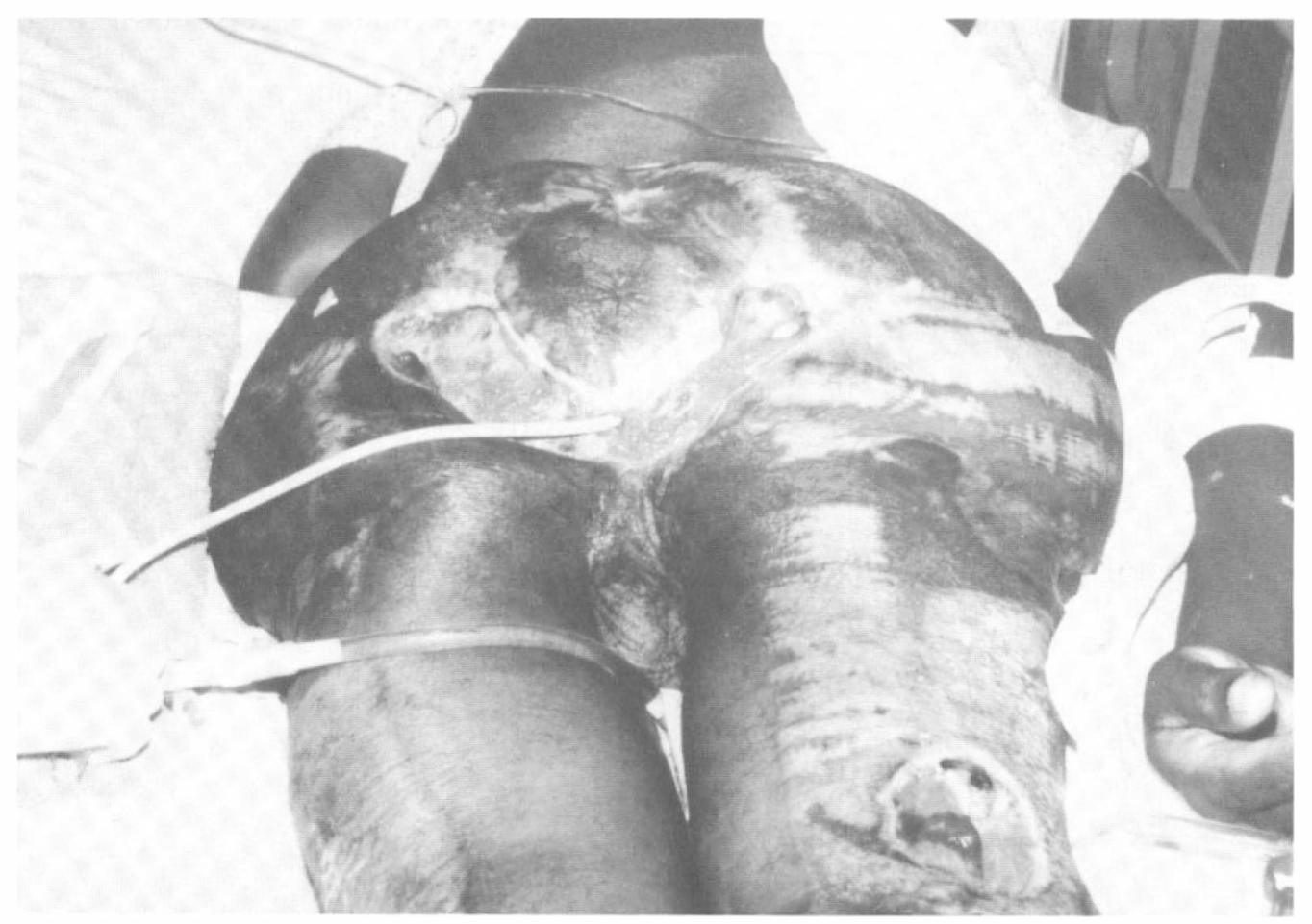

Figure 2 Patient 3 with extensive sacral decubitus.

snugly next to the intubated ileum, fired and the excess tissue removed. A mesenteric window was created at the ileocecal junction to define the ileocecal valve. Three purse string sutures of 3-0 silk were placed at the ileocecal junction, and tied snugly over the indwelling catheter. ${ }^{4-6}$

In the male patients, bladder neck mobilization was performed by incising the prostatovesical neck junction, dissecting the bladder neck posteriorly, allowing upward mobilization. The ureters were identified and protected. In the first 2 patients, the prostatic urethra was oversewn, closed with several interrupted sutures of 0 polyglycolic acid sutures. In the third patient, a radical prostatectomy was performed. The distal urethra was then oversewn, patched in all 3 patients with bovine dura, and covered with mobilized omentum. The intestinal plate was then folded down as an augmentation on the bivalved native bladder and anastomosed with a running interlocking 3-0 vicryl suture in two layers.

In the female patient, the defunctional- ized bladder was left in place draining into the vagina. A complete Miami pouch was then performed as described above, including an antirefluxing nontunneled ureterocolonic anastomosis. ${ }^{4-6}$

In all 4 patients, the tapered ileal stoma was brought flush to the skin. The Mallecot and urinary diversion stents were brought out via separate skin incisions, when ureters were reimplanted.

A sigmoid colostomy was performed in the left lower quadrant. The underlying sigmoid colon was brought to the surface; the TA-90 stapler was used to exclude the distal limb and form a functional end colostomy.

The residual sacral and ischial ulcers were treated conservatively with wet to dry dressings using normal saline.

\section{Results}

The 4 patients have been followed from 6 to 30 months. Postoperatively, intravenous pyelogram and pouchograms have shown 


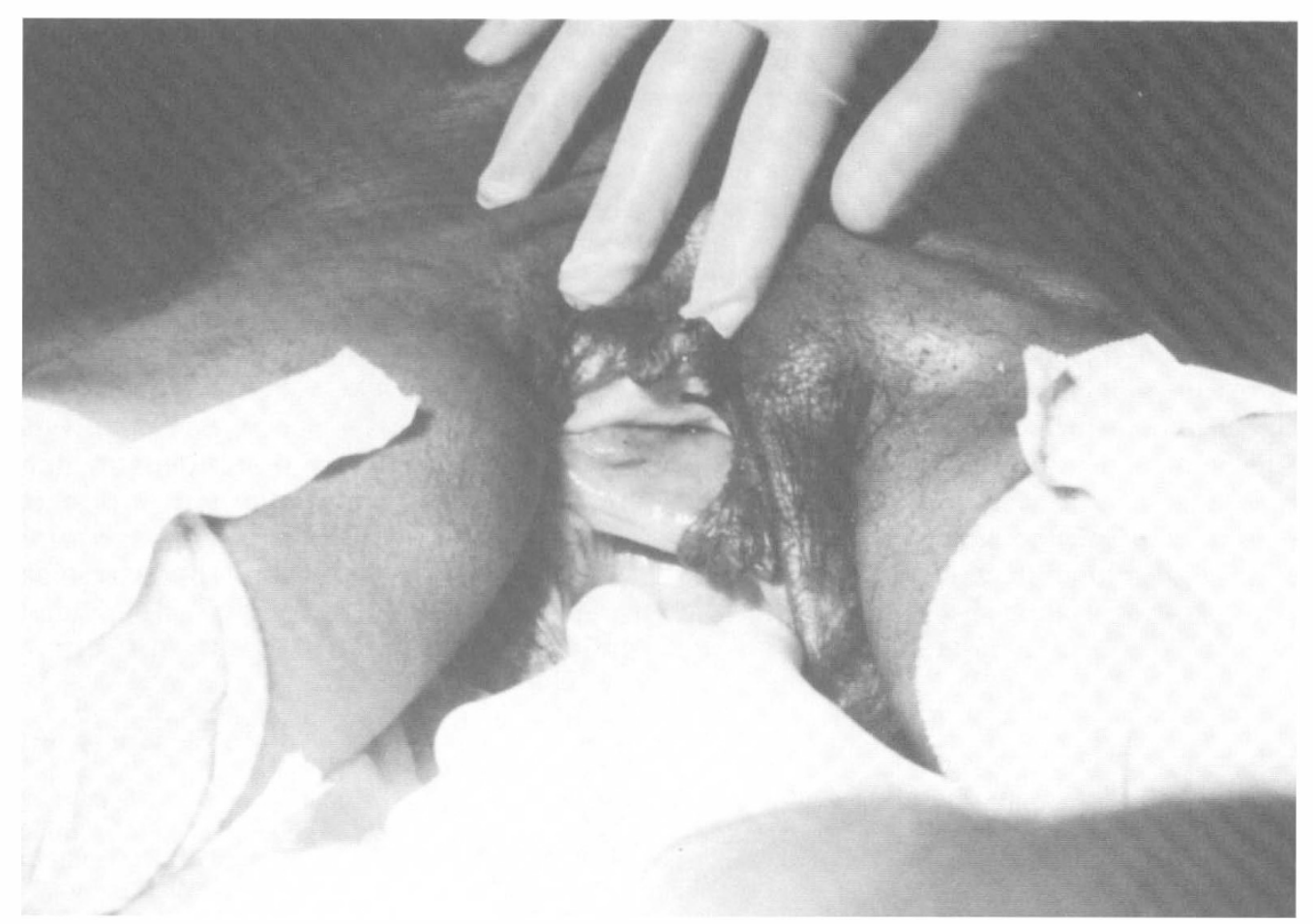

Figure 3 Patient 4 with open bladder neck above the vagina.

neither obstruction nor reflux. Each patient is on a 4-6 hour catheterization program with daily bladder irrigations. All 4 patients are continent of urine.

Urinary and fecal diversion, in conjunction with wet to dry dressings, allowed the pressure sores in all 4 patients to heal. The patients are handling the pouch catheterizations and colostomy bag changes quite well.

\section{Discussion}

Pressure sores have been mentioned in the literature as long as 400 years ago when the suggestion was made that skin ulceration results from nerve severance and loss of blood supply. In 1879, Charcot stated that tissue necrosis was secondary to nerve injury which released a neurotrophic factor causing tissue destruction, leading to the belief that pressure sores were an inevitable complication for a paraplegic patient. ${ }^{7}$ It was not until the 1940s when a new generation of paraplegic patients came back from the war that thoughts on pressure sores became reshaped.

Although many factors contribute to the development of pressure sores, four are critical: pressure, shearing forces, friction and moisture. The essential element of development is pressure, tissue ischemia leading to necrosis. Shear stresses may lead to soft tissue destruction by causing tearing rather than stretching, leading to an ischemic event. ${ }^{2}$ Moisture, caused by either fecal or urinary soilage, reduces skin resistance and predisposes to maceration, increasing the risk of pressure sore formation five-fold. ${ }^{1-3}$

Immobilization and subsequent pressure sore formation is a problem for the paraplegic patient. Untreated ulcers can lead to fever, serious soft tissue infection, sepsis, osteomyelitis and death ${ }^{8-10}$ In this setting, the paraplegic patient may neglect or not be able to effect the positioning required to prevent pressure necrosis/ischemia ulcer formation. Therefore, it is critical that the 


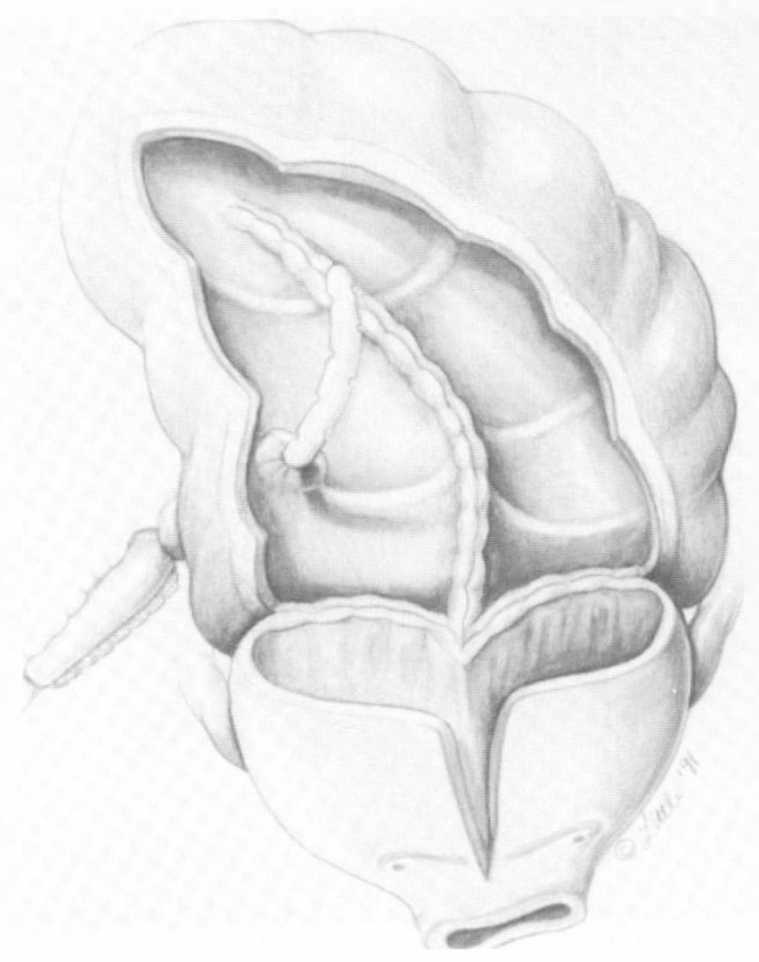

Figure 4 Miami pouch as augmentation onto native bladder.

paraplegic patient be provided with a simple method of personal hygiene that will not foster pressure sore formation.

The first 2 patients underwent bladder neck mobilization without prostate removal. However, the second patient complained of urethral discharge at approximately 6 weeks postoperatively which resolved without incident. This supposed prostatic discharge persuaded us to perform prostatectomy in our third patient.

The male patients were augmented with maintenance of the native trigone, the female required urinary diversion with a Miami pouch, therefore ureteral reimplantation was performed. Previous urinary diversion with closure of the bladder neck and suprapubic tube drainage, obviating ureteral reimplantation, was performed by Hulecki and Hackler. ${ }^{11}$ Their results suffered from decreased bladder capacity (in 6 of 8 patients), with subsequent urinary leakage (2 of 8 patients) and onset of vesicoureteral reflux ( 2 of 8 patients). The patients also required chronic anticholinergic therapy. Webster and Bertram performed a continent ileocecal reservoir in 7 patients: 3 patients had bladder neck closure and augmentation, with a continent stoma being formed by ileocecal valve intussusception; the remaining 4 patients had bladder replacement with a cecal reservoir and continent stoma. ${ }^{12}$ Their results were complicated by incontinence due to evagination of the intussusception ( 1 of 7 patients), and cecal segment hyperactivity ( 3 of 7 patients) requiring chronic anticholinergic therapy. All patients had good upper tract preservation.

The objective of bladder reconstruction should be to create a low pressure storage system, a nonrefluxing ureterointestinal anastomosis, and a reliable continence mechanism. The Miami pouch, with a detubularized, low pressure colonic segment and nontunneled, nonrefluxing uretero- 
colonic anastomosis has provided full incontinence and preservation of upper tract function. ${ }^{4,6}$ It is of interest to monitor upper tract function after Miami pouch diversion in paraplegic patients. Long term follow up of upper tract function in non paraplegic patients with ileal conduit urinary diversion versus upper tract function in the spinal cord injury population has shown progressive deterioration in a significant proportion of both groups $(39 \%$ vs $28 \%$, respectively). ${ }^{13-22}$ The pouch's intestinal segment as an augmentation avoids ureteral reimplantation; the tapered distal ileum and reinforced ileocecal valve allows easy catheterization and provides reliable continence. The paraplegic patient is at a definite advantage without an indwelling catheter and its propensity for chronic infections and associated chronic irritation with possible malignant transformation. ${ }^{23}$ Although malignant transformation has been seen in patients with ureterosigmoidostomies, malignancy of the colonic mucosa has not been described in the continent pouch.

In conclusion, the majority of pressure sores are superficial and can be managed conservatively. In our select group of patients, we have found continent diversion and colostomy formation to be an excellent means to allow deep decubitus ulcers to heal and improve hygienic control in paraplegic patients. Surgery has allowed rehabilitation into a patient who can take care of himself and be gainfully employed.

\section{References}

1 Reuler JB, Cooney TG (1981) The pressure sore: pathophysiology and principles of management. Ann Intern Med 94: 661-666.

2 Sather MR, Weber CE, George J (1977) Pressure sores and the spinal cord injury patient. Drug Intell Clin Pharm 11: 154-169.

3 El-Toraei I, Chung B (1977) The management of pressure sores. J Dermatol Surg Oncol 3: 507-511.

4 Bejany DE, Politano VA (1988) Stapled and nonstapled distal ileum for construction of a continent colonic urinary reservoir. J Urol 140: 491-494.

5 Bejany DE, Suarez G, Penalver M, Politano VA (1989) Nontunneled ureterolonic anastomosis: an alternate to the tunneled implantation. J Urol 142: 961-963.

6 Penalver M, Bejany DE, Averette H, Donato D, Sevin B, Suarez G (1989) Continent urinary diversion in gynecological oncology. Gynecol Oncol 34: 274-288.

7 Vasconez LO, Schneider WJ, Durkiewicz MJ (1977) Pressure sores. Curr Prob Surg 14(4): 1-62.

8 Galpin JE, Chow AW, Bayer AS, Guze LB (1986) Sepsis associated with decubitus ulcers. Am J Med 61: 346-350.

9 Hebel JR, Warren JW (1990) The use of urethral, condom and supra-pubic catheters in aged nursing home patients. J Am Geriatr Soc 38: 777-784.

10 Warren JW, Damron D, Tenney JH, Hoopes JM, Deforge B, Muncie HL (1987) Fever, bacteremia and death as complications of bacteriuria in women with long-term urethral catheters. J Inf Dis 155(6): $1151-1158$.

11 Hulecki SJ, Hackler RH (1984) Closure of the bladder neck in spinal cord injury patients with urethral sphincteric incompetence and irreparable urethral pathological conditions. J Urol 131: 111-112.

12 Webster GD, Bertram RA (1986) Continent catheterizable urinary diversion using the ileocecal segment with stapled intussusception of the ileocecal valve. J Urol 135: 465--469.

13 Hackler RH (1973) Spinal cord injuries-urologic care. Urology 2(1): 13-18.

14 Hackler RH (1977) A 25 year prospective mortality study in the spinal cord injured patient: comparison with the long-term living paraplegic. J Urol 117: 486-488.

15 Comarr AE (1972) Renal complications of the ileal conduit and cutaneous vesicostomy among patients with traumatic cord bladders. J Urol 107: 762-765.

16 Graham SD (1981) Present urological treatment of spinal cord injury patients. J Urol 126: 1-4.

17 Hackler RH (1978) When is an ileal conduit indicated in the spinal cord injured patient? Paraplegia 16: 257-262.

18 O’Donnell WF, Taylor R (1980) Genitourinary problems of spinal cord trauma. Curr Prob Surg 17(4): 216-228.

19 Donnelly J, Hackler RH, Bunts RC (1972) Present urologic status of the WWII paraplegic: 25-year follow-up. Comparison with status of the 20-year Korean war paraplegic and 5-year Vietnam paraplegic. $J$ Urol 108: 558-562.

20 Schwarz GR, Jeffs RD (1975) Ileal conduit urinary diversion in children: computer analysis of followup from 2 to 16 years. J Urol 114: 285-288.

21 Shapiro SR, Lebowitz R, Colodny AH (1975) Fate of 90 children with ileal conduit urinary diversion a 
decade later: analysis of complications, pyelography, renal function and bacteriology. J Urol 114: 289-295.

22 Mitchell ME, Kulb TB, Backes DJ (1986) Intestinocystoplasty in combination with clean intermittent catheterization in the management of vesical dysfunction. J Urol 136: 288-291.

23 Bejany DE, Lockhart JL, Rhamy RK (1986) Malignant vesical tumors following spinal cord injury. J Urol 138: $1390-1392$. 